\title{
A MULHER PESQUISADORA NAS CIÊNCIAS BIOLÓGICAS: TRAJETÓRIAS DE ENFRENTAMENTOS E DE CONQUISTAS*
}

\author{
Aline Lima de Oliveira Nepomuceno ${ }^{1}$ \\ Luiz Ricardo Oliveira Santos ${ }^{2}$ \\ Viviane Almeida Rezende ${ }^{3}$ \\ Bruna Serra de Santana Costa ${ }^{4}$ \\ Marynara Costa Santos ${ }^{5}$
}

\section{Percursos metodológicos e epistemológicos: para que gênero na ciência?}

Segundo Schiebinger (2001), a participação de mulheres na história da ciência foi marcada por ausências e presenças. Nos anos iniciais da Revolução Científica, muitas mulheres envolveram-se com atividades ditas científicas. No entanto, com a institucionalização e a profissionalização da ciência, somadas à separação entre público e privado no contexto do desenvolvimento do capitalismo, a participação da mulher no meio científico ficou mais restrita.

Silva (2012) afirma que, desde os anos 1970, quando a questão do lugar da mulher na ciência passou a se destacar, diversas autoras têm se dedicado a compreender a ausência ou a "suposta" invisibilidade das mulheres na história da ciência, buscando visibilizá-las e mostrando que elas também têm uma história da qual são sujeitos ativos. Desse modo, percebemos que, quando se fala na presença da mulher na história da ciência, é importante lembrar que ela é recente, construída em meio a relações de poder, e observar que a participação da mulher na ciência reflete a distorção históri-

\footnotetext{
${ }^{*}$ DOI - 10.29388/978-65-86678-66-6-f.211-228

${ }^{1}$ Doutora em Educação. Departamento de Biologia, Universidade Federal de Sergipe (UFS).

${ }^{2}$ Doutorando em Desenvolvimento e Meio Ambiente, Universidade Federal de Sergipe (UFS).

${ }^{3}$ Mestra em Educação. Secretaria de Estado da Educação de Sergipe (SEDUC/SE).

${ }^{4}$ Graduanda em Ciências Biológicas Licenciatura, Universidade Federal de Sergipe (UFS).

${ }^{5}$ Graduanda em Ciências Biológicas Licenciatura, Universidade Federal de Sergipe (UFS).
} 
ca presente no fato de que a mulher não aparece como protagonista na história da ciência (SILVA, 2012).

Nas últimas décadas, no Brasil, números significativos passaram a expressar o aumento da presença de mulheres em muitas universidades e instituições de pesquisa do país. Contudo, Silva (2012) assevera que, apesar da crescente participação feminina no mundo da ciência, há evidências de que essa participação vem acontecendo de modo dicotomizado ou está aquém da presença masculina em determinadas áreas.

Diante do exposto, apesar do aumento do acesso das mulheres a diferentes campos da ciência, destacamos que, em determinadas áreas do conhecimento científico, há uma supremacia masculina. Estudos mostram que, mesmo com a maior participação da mulher no sistema brasileiro de Ciência e Tecnologia, elas vêm tendo chances menores de sucesso e de ascensão na carreira. No campo das Ciências Naturais e Exatas, por exemplo, as mulheres são menos contempladas com bolsas de produtividade do CNPq e estão sub-representadas nos cargos administrativos das universidades e entre os membros da Academia Brasileira de Ciências. A mais importante sociedade científica do país, a Sociedade Brasileira para o Progresso da Ciência (SBPC), ao longo de seus 69 anos, teve apenas três mulheres na presidência, e a Sociedade Brasileira de Química (SBQ) contabilizou somente uma mulher presidente, ao longo dos seus 40 anos de existência. Isso evidencia que a trajetória das mulheres na ciência é constituída por uma cultura baseada no "modelo masculino de carreira" (VELHO, 2006).

Nesse contexto, torna-se relevante discutir a participação de muIheres no campo da ciência moderna, mais precisamente nas Ciências Biológicas, em que há uma limitação histórica da ocupação da mulher. Realizamos esse intento tomando como referência as narrativas de mulheres-cientistas atuantes no curso de Ciências Biológicas Licenciatura e/ou Bacharelado, do Departamento de Biologia (DBI) da Universidade Federal de Sergipe (UFS), Campus São Cristóvão, procurando compreender, em suas narrativas, como essas mulheres percebem a sua participação na produção da ciência, o que refletem sobre a feminização e a masculinização de determinadas áreas do conhecimento e quais os desafios, dificuldades e possibilidades presentes nas suas relações acadêmicas com a pesquisa. Na análise das narrativas, buscamos refletir sobre a existência de determinados discursos e práticas sociais produzidos historicamente que, ao interpelarem os sujeitos, ensinam-lhes formas de ser, de agir e de pensar. Assim, ao analisarmos as experiências dessas mulheres na ciência, podemos "explorar como se estabe- 
lece a diferença [e a identidade], como ela opera, como e de que forma ela constitui sujeitos que veem e agem no mundo" (SCOTT, 1999, p. 26).

Trata-se de uma pesquisa de abordagem metodológica qualitativa empregada para a investigação e para o relato analítico de experiências e narrativas realizadas (MINAYO, 1994). Para tornar exequível esta pesquisa, delimitamos os procedimentos metodológicos abaixo descritos.

Como primeira etapa de pesquisa, desenvolvemos a revisão bibliográfica e a pesquisa documental. A revisão bibliográfica objetivou rastrear a atuação histórica da mulher na ciência, as relações de gênero e as experiências de exclusão da mulher da produção científica. Já a pesquisa documental compôs a etapa exploratória, centrada em documentos (cadastros funcionais e matrícula institucional) que, no âmbito local, pudessem refletir a atuação feminina no curso de graduação em Ciências Biológicas Licenciatura e/ou Bacharelado da UFS. Após identificação e seleção dos membros do curso via pesquisa documental, foram aplicados questionários via Google Forms, com o objetivo de conhecer as narrativas e trajetórias de mulheres pesquisadoras vinculadas a esse curso. $O$ recorte temporal adotado situa-se entre os anos de 2012 a 2019, incluindo-se o ano inicial e o final, e tem foco nas questões de gênero e de ciência. Com esse instrumento de produção de dados, buscamos entender melhor o contexto de atuação dessas mulheres.

Todas as participantes/voluntárias da pesquisa assinaram o Termo de Consentimento Livre e Esclarecido (TCLE), construído segundo as normas da Resolução n. 0 466/2012 (BRASIL, 2013). O termo citado garante a autonomia, o sigilo e o anonimato dos depoimentos, além de descrever os benefícios diretos ou indiretos da pesquisa para as participantes/voluntárias. Após a seleção da amostra, foi possível o envio por e-mail dos formulários/questionários para quinze docentes do $\mathrm{DBI}$, com retorno de seis docentes, que foram renomeadas no texto para que suas identidades fossem preservadas. Os nomes adotados são os de pesquisadoras brasileiras também biólogas que se destacaram nacionalmente e internacionalmente no campo científico (Helga Winge, Sonia Dietrich, Graziela Maciel, Bertha Lutz, Diana Mussa e Reinalda Marisa).

O fato de o coletivo da pesquisa ser constituído por um número reduzido de participantes, obtido pelo baixo número de respostas aos questionários, não desqualifica a investigação, tendo em vista que, desde o início, não possuíamos a intenção de criar generalização de resultados. Do ponto de vista das narrativas e dos discursos, a atividade, e tudo que a envolve, é observada de maneira singular. Neste caso, a análise da opinião 
das pesquisadoras quanto às suas respectivas inserções no campo científico se baseia no entendimento da singularidade que caracteriza o fazer de cada uma das envolvidas, sem que percamos de vista as questões comuns ao trabalho de todas.

As discussões e análises aqui traçadas estão situadas em uma perspectiva crítica, o que contribui para uma (re)interpretação história dos lugares e das experiências das mulheres, destacando-se a presença destas nas ciências e nas instituições de produção científica com vistas a problematizar o lugar da ciência moderna em meio a uma cultura hegemônica que tem seus pilares no sexismo e no androcentrismo.

\section{A inserção das mulheres na ciência: narrativas de mulheres cientistas sobre a escolha profissional}

Ao procedermos à análise das respostas dadas ao formulário de perguntas, foi-nos possível construir um breve perfil das pesquisadoras questionadas, principalmente no tocante às áreas de atuação e ao tempo de experiência na pesquisa científica. Os dados revelam que a maioria das professoras pesquisadoras do DBI-UFS possui doutorado $(62,5 \%)$, sendo que $37,5 \%$ concluíram o pós-doutorado. Os campos da última formação dessas mulheres vinculadas ao DBI envolvem áreas diversas, tais como: Etnobiologia (16,6 \%), Entomologia (16,6\%), Ensino (16,6\%), Botânica $(16,6 \%)$, Biotecnologia (16,6\%) e Gênero e Cultura Audiovisual (16,6\%). Essa diversidade de áreas de atuação mostra que a mulher vem ocupando diversos espaços na produção científica dentro da Universidade. No caso das questionadas, foi possível identificar que suas pesquisas estão relacionadas aos campos das Ciências Humanas (25\%), das Ciências Biológicas (50\%) e, ainda, das Ciências Sociais (12,5\%).

Com relação à atuação das mulheres na pesquisa científica, os dados apontam que a maioria das participantes $(62,5 \%)$ exerce a função de pesquisadora há mais de 10 anos. Ademais, podemos constatar que todas estão vinculadas a grupos de pesquisas, sendo que $25 \%$ participam desses grupos há um período entre 1 e 5 anos, 37,5\% participam entre 5 e 10 anos e $37,5 \%$ participam há mais de 10 anos. Ainda sobre a atuação no campo científico, observamos que todas as pesquisadoras já coordenaram projetos de pesquisa, porém nem todos obtiveram financiamento. Dos projetos coordenados, $25 \%$ foram financiados e $25 \%$ não receberam recursos. Sobre 
esse ponto, $50 \%$ das mulheres disseram que alguns dos projetos que coordenaram obtiveram financiamento e outros não.

No que se refere à experiência como docentes, metade das mulheres questionadas afirmou ter entre 5 e 10 anos de atuação, enquanto a outra metade disse atuar há um período entre 5 e 10 anos na docência universitária. Quanto ao tempo de experiência no DBI, identificamos que metade das professoras/pesquisadoras questionadas têm entre 1 e 5 anos de atuação e que apenas $12,5 \%$ possui mais de 10 anos vinculados a esse departamento. Ainda sobre o campo ocupado por essas mulheres na Universidade, identificamos que $50 \%$ delas têm vínculos com a pós-graduação.

A partir desses dados, observamos que pesquisadoras do DBI vêm, ao longo do tempo, envolvendo-se com o campo da produção científica de forma expressiva, seja atuando na coordenação e grupos de pesquisas, seja na pós-graduação. Entender, a partir das suas narrativas, como essas muIheres vêm traçando esse caminho, de forma a conhecer lutas, conquistas, desafios e obstáculos peculiares à trajetória feminina no campo da ciência, é de fundamental importância para o debate acerca da necessidade de se ampliar o espaço de atuação das mulheres no meio científico, situando os conhecimentos produzidos por elas nas especificidades de seus tempos, espaços, condições objetivas e subjetivas.

\section{Gênero na(s) ciência(s)}

A luta das mulheres contra os padrões impostos pela sociedade, que as limitam de ter vivência no campo científico, não começou recentemente. A exclusão da mulher do âmbito da ciência ainda era vista nas primeiras décadas do século XX, quando se tratava a ciência como uma ocupação inadequada às mulheres, e, na segunda metade do mesmo século, havia uma rotulação das profissões que as dividia em masculinas e femininas (CHASSOT, 2004).

A exclusão da mulher do meio científico perpassa primeiramente pelas questões de gênero, pois, quando a ciência é caracterizada como masculina, torna-se excludente de quem não se encaixa nesse padrão. Assim, há uma valoração hierárquica nas Ciências Naturais e Exatas, também conhecidas como ciências "duras", as quais são marcadas pela objetividade e, por isso, são postas como contrárias às Ciências Humanas e Sociais, denominadas "moles", pois estudam temas mais subjetivos e próprios das inte- 
rações sociais. Dessa forma, as ciências "duras" são comumente relacionadas aos homens e as ciências "moles", às mulheres (DA SILVA, 2008).

Nessa perspectiva, observamos, por exemplo, que esses conceitos são difundidos pelos meios de comunicação de forma estereotipada e reducionista, com marcas de um perfil de cientista que não corresponde à realidade. Entre outros atributos, são conferidos aos personagens do meio científico características como "diferente, esquisito, persistente, inteligente, original, incrível e maluco" (CARDOSO, 2016), além do uso de "roupa de cientista", o jaleco (SIQUEIRA, 2006). Não devemos esquecer que essas representações são atribuídas, em sua maioria, a um homem branco que trabaIha trancafiado em seu laboratório enquanto se esforça para realizar uma grande descoberta. As mulheres, por sua vez, aparecem em segundo plano, como meras coadjuvantes, alheias a qualquer produção intelectual e, até mesmo, de forma abobalhada. Tais constatações demonstram que essas informações, que são de fácil acesso, agem no imaginário das pessoas e contribuem com a conservação de ideias ultrapassadas do que é ciência e de quem a faz.

Se, por um lado, existem padrões que reforçam a visão limitada do que é ser cientista, por outro há uma quantidade significativa de mulheres que buscam preencher os espaços. No Brasil, segundo dados do Conselho Nacional de Desenvolvimento Científico e Tecnológico (CNPq), no ano de 2015 foram concedidas 5.013 (35,5\%) bolsas de produtividade em pesquisa a mulheres, enquanto os homens foram contemplados com o total de 9.092 $(64,5 \%)$ bolsas. Ou seja, as mulheres precisam enfrentar fatores que vão desde concepções restritivas até a falta de apoio financeiro na pesquisa, proveniente da má distribuição de bolsas ou resultante de fatores alheios à profissão, como a maternidade, por exemplo.

Sendo assim, podemos dizer que existem diferenças entre ser muIher cientista e ser homem cientista. O enfrentamento de dificuldades ocorre naturalmente em qualquer campo de estudo, no entanto, durante a trajetória feminina, encontram-se obstáculos que os homens jamais encontrarão, pelo único motivo de não serem mulheres, como expressa a pesquisadora Helga Winge:

E estar dividindo a atenção entre os compromissos profissionais e a autodefesa para não permitir que me sejam impostos limites e barreiras discriminatórios (muitas vezes velado) em função do meu gênero. 
Soma-se a isso, a conciliação com os outros papéis, como a maternidade integral (pais ausentes).

Em seu discurso, Helga cita a "autodefesa", revelando que precisa realizar uma força contrária, necessária para esquivar-se de discriminações "em função do seu gênero". Além disso, atribui à sua definição de ser muIher cientista o fato de que algumas mulheres têm que conciliar a profissão com o papel de mãe solo. Sobre isso, importa trazermos dados do estudo Retrato das Desigualdades de Gênero e Raça realizado pelo Instituto de Pesquisa Econômica Aplicada (IPEA), com indicadores do IBGE, os quais revelam que, no ano de $1995,23 \%$ dos domicílios eram chefiados por mulheres; já no ano de 2015 , foi contabilizada a porcentagem de $43 \%$ de mulheres que chefiam seus lares. Ainda dentro dessa porcentagem (43\%), 34\% apresentam um cônjuge, mas este não é tido como pessoa referência do domicílio (BONETTI et al., 2017). Com isso, podemos observar que muitas mulheres estão sozinhas na jornada materna e que outras, ainda que estejam acompanhadas, assumem a responsabilidade sozinhas.

Como já dito, existe em torno da produção científica um estigma enraizado no íntimo das pessoas, proveniente da caracterização da ciência como sendo objetiva, neutra, transparente e universal, caracterização essa que sustenta o método científico e que deixa à margem tudo aquilo que não faz parte desses princípios. Nesse caso, as mulheres, muitas vezes, são criticadas e subestimadas em suas escolhas profissionais, por serem vistas como a oposição de tudo aquilo que a ciência representa. Ainda nesse contexto, há quem discrimine a posição da mulher na ciência com base no determinismo biológico, ou seja, em teorias que reforçam que as ocupações em determinadas áreas são limitadas por fatores biológicos (CITELI, 2001).

Desse modo, mesmo que haja objeção quanto à forma de se "fazer ciência", para algumas pesquisadoras ser mulher cientista representa "trabalhar com afetos em um campo que limita o sentir" (Sonia Dietrich); "a diversidade de olhares, amplia as leituras que a ciência produz". (Helga Winge); "uma representação da mudança de paradigma" (Bertha Lutz). Percebemos, na fala das pesquisadoras, que o "afeto" e a "diversidade de olhar" aparecem como algo que traz vantagem para a produção científica, mas que, no entanto, é passível de descredibilidade. Ao analisar a fala de Bertha Lutz, "mudança de paradigma", compreendemos que ser mulher na ciência contribui, em menor ou maior grau, para a transformação do que antes era rígido e imutável, o que não torna as mulheres livres de qualquer 
forma de preconceito e de exclusão, pois a quebra de um paradigma não exclui necessariamente a existência de outro, podendo os dois coexistirem (MAYR, 2005).

Assim, ainda que exista maior ocupação feminina no campo científico, o número de mulheres, na escala global, que se dedicam à ciência ainda é menor que o número de homens (CHASSOT, 2004). Historicamente, além da desigual participação da mulher, era comum não haver o reconhecimento de seu trabalho. Por isso, são tão importantes os questionamentos "Qual a importância da inclusão das mulheres na(s) ciência(s)?" e "Como essa inclusão pode impactar na produção científica?, pois trazem consigo a percepção e as possibilidades de mudanças. Alguns olhares sobre essa inclusão são retratados pelas pesquisadoras:

[..] visa a equidade, que se atenta às necessidades de pesquisadoras que são mães, como p.ex., a garantia de licença maternidade, day care em congressos [..]. (Reinalda Marisa)

A inclusão de novos pesquisadores (independente do gênero) alavanca a ciência, tornando-a diversificada, mais abrangente. (Bertha Lutz)

Acredito que a relevância da inclusão de mulheres na Ciência esteja resguardada no exemplo a outras meninas que querem seguir este caminho. [..] as meninas poderiam ver que não há áreas típicas de mulheres ou típicas de homens [...]. (Graziela Maciel)

A Ciência como carro chefe da transformação da sociedade, não pode ser conduzida somente por homens, ou teremos uma transformação covardemente enviesada. (Helga Winge)

Vemos que a equidade foi citada por Reinalda Marisa como o alvo que se pretende atingir com a inclusão. Aqui ressaltamos a importância da distinção entre "equidade" e "igualdade". Apesar de os dois vocábulos apresentarem definições semelhantes no contexto em que se inserem, um apresenta maior completude do que o outro. Segundo o dicionário Oxford Language, equidade expressa

[...] virtude de quem ou do que (atitude, comportamento, fato etc.) manifesta senso de justiça e igualdade 'fato de não se apresentar diferença de qualidade ou valor, ou de, numa comparação, mostrarem- 
se as mesmas proporções, dimensões, naturezas, aparências, intensidades; uniformidade; paridade; estabilidade' (ORXFORD LANGUAGENS AND GOOGLE, 2020, s/p).

Desse modo, a equidade é uma forma de justiça que busca atender a todos de acordo com as suas necessidades reais, enquanto a igualdade não contempla os diversos pontos de partida das dificuldades sociais. Um exemplo prático dessa diferença na vida da mulher remete diretamente à igualdade de gênero: o fato de que, durante o período de licença maternidade, um direito garantido como uma forma de igualar as condições de trabalho entre mulheres e homens, a produção científica da mulher é reduzida, pois não há políticas públicas capazes de conciliar a vida acadêmica com esse período de desdobramento da mulher. Logo, o que se tem como resultado é a discrepância entre as produções intelectuais dos homens e das mulheres.

A inclusão feminina na ciência também contribui, de acordo com Bertha Lutz e Graziela Maciel, para que a ciência torne-se "diversificada, mais abrangente" e "resguardada no exemplo a outras meninas que querem seguir este caminho". Assim sendo, abrem-se as portas da representatividade, para que as novas gerações de meninas se espelhem nas mulheres cientistas e possam contribuir para a transformação da sociedade sem que seja "conduzida somente por homens" e, dessa maneira, "covardemente enviesada", como citou Helga Wilge.

Logo, diante de um cenário histórico marcado pela exclusão e pela luta por conquistas, as mulheres ainda enfrentam diversas questões em seu cotidiano, dentre as quais estão as relacionadas à carreira no campo científico. Ainda não findaram os fatores limitantes à ascensão da mulher, por isso o que resta é buscar estratégias para combater as formas de pensamentos e de ações excludentes, em busca da equidade entre homens e muIheres não só na ciência, mas também em outros campos.

\section{Tornar-se mulher/tornar-se cientista}

Um dos maiores dilemas que a mulher encontra na atuação e na permanência na área acadêmica é a conciliação de identidades: como ser mãe e cientista ao mesmo tempo? A relação social construída entre a muIher e a maternidade, na qual há uma responsabilidade redobrada da muIher para com seus filhos, foi amplamente debatida a partir da década de 
1970, em que estudos aprofundados sobre as questões de gênero criticaram a atribuição de naturezas femininas e masculinas, partindo da perspectiva de que as diferenças entre os sexos foram culturalmente produzidas baseando-se em aspectos biológicos como, por exemplo, a atividade reprodutiva da mulher, para naturalizarem-se responsabilidades socialmente construídas (ZULATO-BARBOSA; ROCHA-COUTINHO, 2012).

Outro desafio imposto à mulher cientista é o enfrentamento e a conciliação da dupla jornada de trabalho: as atividades domésticas e acadêmicas. Como se dedicar "integralmente" - assim como fazem os homens - à carreira científica, visto que os pilares sobre os quais a ciência foi construída exigem, muitas vezes, uma postura de doação quase integral do/a cientista ao seu trabalho? Será que esses pilares que serviram de base à construção da ciência garantem a inclusão e a permanência das mulheres na carreira científica? A realidade que subsidia as respostas a essas questões revela que a dupla jornada de trabalho torna-se um agravante de todos os obstáculos que a mulher já enfrenta dentro da carreira científica.

Para as docentes participantes deste estudo, a conciliação da jornada dupla ou tripla de trabalho é um fator decisivo para o sucesso dentro da carreira científica. Podemos observar, no discurso a seguir, como elas percebem as dificuldades da compatibilização dos trabalhos domésticos e acadêmicos, principalmente no tocante à produtividade científica:

Vejo uma pressão relacionada à produção científica como um todo. Mulheres com jornada dupla acabam sofrendo mais, pois muitas vezes não conseguem acompanhar o ritmo imposto. Já vivi esse dilema e decidi que a pesquisa faz parte do meu trabalho, do meu "ganha pão", e que não deve ser mais importante do que os dias em família e com amigos. Eu assumi os bônus e ônus dessa decisão e vivo bem com eles, apesar de estes últimos significarem menor produção científica. (Graziela Maciel)

Dessa forma, a pesquisadora-mulher-mãe acaba tendo uma jornada excessiva de trabalho para conseguir dar conta das atividades domésticas e acadêmicas e, com isso, tem dificuldades em conseguir se destacar na carreira científica, pois esta exige uma dedicação muito grande que é inconciliável com a vida da mulher-mãe-dona de casa (SILVA; RIBEIRO, 2014). Estudos desenvolvidos por Ramos e Tedeschi (2015), ao analisarem a produtividade de professores/as do Instituto de Biologia da UNESP, evidenciam que, 
apesar de as mulheres estarem em igualdade numérica com os homens, a produtividade científica deles ainda é maior, o que pode se dar graças a questões como maternidade, trabalho doméstico e adequação de recursos científicos.

Ademais, mesmo com uma maior inserção das mulheres na carreira científica e na esfera pública, elas ainda arcam com responsabilidades da esfera privada que são socialmente atribuídas às mulheres. Para Schmidt (2012, p. 5), tais responsabilidades são justificadas em termos biológicos, consubstanciadas por características atribuídas ao feminino, como "paciência, delicadeza e passividade", as quais determinam os papéis femininos na sociedade. Nessa perspectiva, as dificuldades encontradas pelas mulheres, no tocante à construção e à consolidação da carreira, para além das que são comuns aos homens, recaem em materializações discursivas biologizantes, as quais naturalizam, em enunciados científicos e biológicos, posicionamentos machistas e sexistas.

Somada às questões de produtividade, as docentes relataram a presença de vieses sexistas e androcêntricos, referidos pelas pesquisadoras participantes na forma de imposição de posturas e de condutas específicas para o exercício da atividade científica, o que dificulta, portanto, a interseção entre o ser mulher e o ser cientista; "Conflitante. O dilema é a imposição de posturas com a intenção de dificultar essa intersecção. Sim, desde o início da carreira até hoje. Em alguns períodos impactou reduzindo a produtividade" (Helga Winge).

Nesse contexto, para além das questões trabalhistas e familiares, a dedicação à carreira e à pesquisa acarreta, com base no enunciado de uma das pesquisadoras, empecilhos na promoção de inter-relações afetivas com os homens, por causa da visão patriarcal tão enraizada nos princípios da nossa sociedade:

Sem dúvida, da forma como se organiza o trabalho cientifico entre as demandas universitárias de ensino, pesquisa e extensão, há uma grande sobrecarga para a vida familiar. Divisão de tarefas, cuidado de filhos/as, desgaste nas relações de intimidade e familiares, são alguns dilemas amplamente estudados. Pessoalmente, pela qualificação profissional, enfrentei dificuldades para estabelecer relações amorosas (o que é bem comum entre mulheres doutoras), pois a insegurança masculina se evidencia fortemente. (Reinalda Marisa) 
Dadas as diversas atribuições e os diferentes papéis sociais desempenhados pelas mulheres, procuramos saber se, em algum momento durante a atuação científica das pesquisadoras, houve interrupção/afastamento do trabalho. A maioria $(83,3 \%)$ das mulheres informou que nunca precisou se afastar do trabalho. No entanto, embora uma das questionadas tenha informado que nunca necessitou do afastamento, ela afirmou que seguiu "[...] efetiva mesmo adoecida" (Helga Winge). Essa colocação revela que, muitas vezes, a mulher precisa enfrentar processos marcados por pressões e estresses que podem provocar impactos negativos em sua saúde. Ainda sobre a questão do afastamento do trabalho, apenas uma pesquisadora afirmou ter se afastado por motivos de gestação, ainda que não tenha relatado os impactos desse afastamento na sua produção científica.

Contudo, apesar dos grandes desafios observados e vivenciados por essas mulheres (professoras/mães/esposas/pesquisadoras), é evidenciado o crescimento da produção científica no DBI, o que reflete a necessidade de se continuar discutindo e refletindo acerca do posicionamento da mulher diante das carreiras acadêmicas. Acerca do protagonismo científico no departamento, relata uma professora:

Penso que ainda há muitos desafios, especialmente em alguns campos. Por outro lado, o protagonismo, visibilidade e relevância das pesquisas realizadas por/com mulheres é cada vez mais relevante. No $D B I$, esta ocupação é relevante, o que pode ser visto pelo número de docentes em programas de pós-graduação, com projetos aprovados em agências de fomento. (Reinalda Marisa)

Para Leta (2003, p. 275), o aumento da presença feminina na academia foi imprescindível para "seu acesso e incorporação aos quadros das universidades [...] não se tratando apenas de um crescimento de demanda, mas de uma demanda mais bem qualificada". Assim, mesmo diante das adversidades e das lutas cotidianas, travadas em âmbitos particular e laboral, observamos que a construção social existente entre se tornar mulher/tornar-se cientista perpassa por distintos (re)começos, os quais devem ser amplamente problematizados na academia e na sociedade, principalmente no tocante a atitudes sexistas. 


\section{Sexismo na(s) ciência(s)}

Ao traçarmos uma análise da trajetória de mulheres na produção científica, é possível que percebamos o quanto essa caminhada é marcada por muitas conquistas e avanços, mas também por inúmeros desafios que envolvem questões de gênero manifestadas nas relações de poder e nas vivências cotidianas no campo científico em que essas mulheres são inseridas.

Ao considerarmos que o preconceito e a discriminação contra as mulheres "não é atual, nem conjuntural, mas sim histórico e estrutural" (TRIGO, 2015), entendemos que, ao longo do tempo, a ciência tem sido legitimada por uma prática androcêntrica, na qual o conhecimento científico é produzido em conformidade com o sexismo e a heteronormatividade (LIMA, 2008). Sendo assim, de acordo com Lima (2008), o meio científico, apesar de seu discurso de distanciamento e de neutralidade, é munido pelas lógicas que configuram a sociedade e, dentre elas, está o gênero.

Nessa conjuntura, o gênero não pode ser descontextualizado do seu chão patriarcal, vez que revela uma relação de hierarquia em que o feminino está subjugado ao masculino. De acordo com Silva e Ribeiro (2014), as relações de gênero que se estabelecem no cotidiano das universidades e das instituições de pesquisa são atravessadas por relações de poder que (re)produzem identidades e diferenças. Destarte, a ciência, como um construto humano, não está isenta das múltiplas formas de preconceito e de discriminação de gênero.

Embora as mulheres venham ocupando cada vez mais espaços na produção da ciência, ainda existem muitas que se deparam com situações de preconceito e de discriminação. Para sabermos quais as vivências das pesquisadoras no que se refere ao sexismo na ciência, foi-lhes perguntado o seguinte: Você já foi vítima de preconceitos e de discriminação na produção científica por ser mulher? Se não foi vítima, você já presenciou mulheres em situação de discriminação em seu campo de atuação?

$\mathrm{Na}$ análise das respostas obtidas, observamos que $50 \%$ das questionadas responderam que não sofreram e nem presenciaram discriminação e/ou preconceitos relacionados ao gênero no campo em que atuam. No entanto, as diferentes facetas do preconceito de gênero foram expostas em algumas das experiências narradas, como pode ser percebido nos discursos a seguir: 
Sim. Fui abandonada em campo pelo mateiro indignado com uma mulher trabalhando em ambiente florestal. Também fui assediada, diversas vezes por colegas de trabalho (Helga Winge)

Pessoalmente, já vivi um confronto em um congresso que participei. Um rapaz muito agressivo, disse que o que eu estava dizendo não era ciência (o tema era transexualidade) e que a biologia não dizia assim. Como eu estava na mesa, pude respondê-lo, com base nos estudos e pesquisas que faço. (Reinalda Marisa)

Há gestores da instituição que em momentos de debates ignoram meu gênero verdadeiro, me tratando pelo gênero biológico como forma de me desestabilizar emocionalmente. Acho isso abusivo. (Sonia Deitrich)

Nos discursos trazidos pelas mulheres que já sofreram preconceito/discriminação em suas atividades científicas, é possível verificar que o fator "ser mulher" é tido, muitas vezes, como uma causa excludente e serve de justificativa para atitudes que as inferiorizam, como demonstrado nos casos relatados nas narrativas de Helga e Reinalda. O relato de Helga revela que mulheres ainda convivem com discursos que naturalizam a ideia de que as condições femininas no campo da produção científica são limitadas. Nesse contexto, reforça-se uma desvalorização das características femininas e uma supervalorização das habilidades masculinas, considerando-se essas últimas mais aptas a produzir o conhecimento científico.

Sobre isso, vale destacarmos que, de acordo com Silva e Ribeiro (2014, p. 456), a crítica feminista à ciência problematiza "o entendimento de que a produção da ciência legítima se dá a partir dos valores associados ao masculino, dos quais as mulheres são consideradas naturalmente desprovidas".

Reinalda Marisa ainda explicita a existência da violência sexual quando afirma o seguinte: "Também fui assediada, diversas vezes por colegas de trabalho". O assédio sexual, entendido como um tipo de violência praticada contra as mulheres, revela-se como mais uma forma de dominação do masculino sobre o feminino e se apresenta em diferentes espaços sociais, incluindo-se as instituições de produção científica, o que acaba exigindo das mulheres movimentos de resistência e de luta para se manterem num contexto de coexistência com o masculino. Sendo assim, o 
assédio se configura com um elemento determinante da segregação feminina na produção científica.

O discurso de Sonia Deitrich revela outro processo de discriminação de gênero, voltado, nesse caso, à sua condição de transgênero. O processo de transfobia enfrentado especialmente por mulheres trans mostra que o espaço acadêmico também pode se constituir como lócus de reprodução de preconceitos que acabam reforçando segregações, quando essas pessoas são julgadas como alheias à realidade heteronormativa. Nesse sentido, é fundamental enfrentarmos e combatermos as desigualdades socialmente, culturalmente e historicamente produzidas entre os gêneros, que determinam e naturalizam as funções realizadas pelos indivíduos com base em aspectos biológicos.

Assim, a discussão acerca da perspectiva de gênero na cultura da ciência é de grande importância, de forma a desvelar-se que a produção do conhecimento científico ainda é pautada pela cultura patriarcal, que normatiza e legitima os discursos, os comportamentos, os códigos e as posturas. Sem esse reconhecimento, não é possível empreendermos as lutas e as ações capazes de ultrapassar os obstáculos impostos pela questão de gênero à ciência.

\section{Onde estão as biólogas cientistas?}

Muito se tem alcançado, e maiores têm sido os desafios no que diz respeito à ocupação da mulher no meio acadêmico. No entanto, notamos, ao longo do estudo, que as diferenças de gênero promovem lentidão e maior complexidade no processo de inserção das mulheres no meio acadêmico profissional, o que também pode ser observado no DBI.

$\mathrm{Na}$ análise das narrativas, evidenciamos que as pesquisadoras entrevistadas se defrontaram e se defrontam com um conjunto de "barreiras" em suas carreiras científicas, as quais se referem à dupla jornada de trabaIho, à maternidade, à produtividade em pesquisa, à competição, ao preconceito e à discriminação de gênero. Desse modo, foi possível a nós perceber que as pesquisadoras do DBI foram, de alguma forma e em algum momento de suas carreiras profissionais, interpeladas pelo "modelo masculino" de pensar e de fazer ciência, não apenas para serem consideradas cientistas, mas também para serem bem-sucedidas na profissão. 
Em síntese, ainda imperam sobre a sociedade alguns estereótipos que precisam ser amplamente trabalhados e discutidos em todos os setores sociais, especialmente no que se refere à inclusão da mulher em certas áreas do conhecimento. Nesse contexto, surge a importância do papel da família e da escola de trabalhar esses estereótipos, de modo a promover um equilíbrio cultural entre homens e mulheres, estabelecendo uma relação de igualdade entre ambos.

A escola, como parte da educação formal, possui papel fundamental na promoção e no incentivo de uma educação científica para todos homens e mulheres - que os torne capazes de enfrentar os desafios impostos pela ciência, especialmente no que se refere à inclusão das mulheres, as quais devem ser reconhecidas como pessoas de direitos e que anseiam por equidade e visibilidade. A partir desse reconhecimento, a ciência poderá abrir mais espaço para novas cientistas e promover a igualdade de gêneros tão relevante para os avanços na produção científica.

\section{Referências}

BONETTI, Alinne et al. Retrato das Desigualdades de Gênero e Raça-1995 a 2015. Instituto de Pesquisa Econômica Aplicada, p. 1-5, 2017.

BRASIL. Ministério da Saúde. Resolução n.o 466, de 12 de dezembro de 2012. Aprova as diretrizes e normas regulamentadoras de pesquisas envolvendo seres humanos. Diário Oficial da União, Brasília, DF, 13 jun. 2013.

CARDOSO, Lívia de Rezende. Relações de gênero, ciência e tecnologia no currículo de filmes de animação. Revista Estudos Feministas, v. 24, n. 2, p. 463-484, 2016.

CHASSOT, Attico Inácio. A ciência é masculina? É, sim senhora!... Contexto e Educação, Editora UNIJUÍ, ano 19, n. 71/72, p. 9-28, 2004.

CITELI, Maria Teresa. Fazendo diferenças: teorias sobre gênero, corpo e comportamento. Revista Estudos Feministas, v. 9, n. 1, p. 131-145, 2001. 
CNPQ. Ministério da Ciência, Tecnologia e Inovações. Bolsas de Produtividade em Pesquisa por categoria/nível segundo o sexo do bolsista - 20012015. Disponível em: http://www.cnpq.br/web/guest/series-historicas/. Acesso em: 16 set. 2020.

DA SILVA, Elizabete Rodrigues. A (in) visibilidade das mulheres no campo científico. Travessias, v. 2, n. 2, 2008.

LETA, Jacqueline. As mulheres na ciência brasileira: crescimento, contrastes e um perfil de sucesso. Estudos Avançados, São Paulo, v. 17, n. 49, p. 271284, 2003.

LIMA, Betina Stefanello. Teto de vidro ou labirinto de cristal? As margens femininas das ciências. 2008. 133 f. Dissertação (Mestrado em História) Universidade de Brasília, Brasília, 2008.

MAYR, Ernst. As revoluções científicas de Thomas Kuhn acontecem mesmo? In: MAYR, Ernst. Biologia, ciência única. São Paulo: Companhia das Letras, 2005.

MINAYO, Maria Cecília de Souza. Ciência, técnica e arte: o desafio da pesquisa social. In: MINAYO, Maria Cecília de Souza et al. (Orgs.). Pesquisa social: teoria, método e criatividade. 2. ed. Petrópolis: Vozes, 1994. p. 9- 29.

ORXFORD LANGUAGENS AND GOOGLE. Oxford Languages, 2020. Disponível em: https://languages.oup.com/google-dictionary-pt. Acesso em: 16 set. 2020.

RAMOS, Renan Carvalho; TEDESCHI, Samara Pereira. A participação das muIheres na produção científica da UNESP, Campus de Rio Claro. Caderno Espaço Feminino, Uberlândia/MG, v. 28, n. 1, p. 140-151, jan./jun. 2015.

SCHIEBINGER, Londa. O feminismo mudou a ciência? São Paulo: EDUSC, 2001. 
SCHMIDT, Natalia Taiza. A dupla jornada de trabalho: reflexão sobre o vínculo da mulher com o trabalho doméstico em contexto de ensino e aprendizagem de sociologia para o nível médio. Ensino de Sociologia em Debate, Londrina/PR, v. 1, n. 1, p. 1-11, jan./jun. 2012.

SCOTT, Joan. Gênero: uma categoria útil de análise histórica. Educação \& Realidade, Porto Alegre, v. 20, n. 2, p.71-99, 1999.

SILVA, Fabiane Ferreira da; RIBEIRO, Paula Regina Costa. Trajetórias de muIheres na ciência: "ser cientista" e "ser mulher". Ciência \& Educação (Bauru), Bauru, v. 20, n. 2, p. 449-466, 2014.

SILVA, Fabiane Ferreira da. Mulheres na ciência: vozes, tempos, lugares e trajetórias. 2012. 148 f. Dissertação (Mestrado em Educação em Ciências: Química da Vida e Saúde) - Universidade Federal do Rio Grande, Rio Grande, RS, 2012.

SIQUEIRA, Denise da Costa Oliveira. O cientista na animação televisiva: discurso, poder e representações sociais. Em questão, v. 12, n. 1, p. 131-148, 2006.

TRIGO, Luiz Gonzaga Godoi. As milenares origens do preconceito de gênero. Revista Turismo \& Desenvolvimento, n. 23, p. 37-47, 2015.

VELHO, Léa. Prefácio. In: SANTOS, Lucy Woellner; ICHIKAWA, Elisa Yoshie; CARGANO, Doralice de Fátima (Orgs.). Ciência, tecnologia e gênero: desvelando o feminino na construção do conhecimento. Londrina: IAPAR, 2006.

ZULATO-BARBOSA, Patrícia; ROCHA-COUTINHO, Maria Lúcia. Ser mulher hoje: a visão de mulheres que não desejam ter filhos. Psicologia \& Sociedade, v. 24, n. 3, p. 577-587, 2012. 